\title{
Effects of 12-month Antiepileptic Drug Use on Thyroid Functions in Children: A Retrospective Observational Study
}

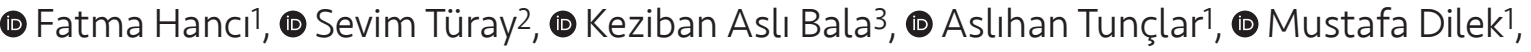 \\ (1) Nimet Kabakuş1 \\ 1Bolu Abant İzzet Baysal University Faculty of Medicine, Department of Pediatrics, Bolu, Turkey \\ 2Düzce University Faculty of Medicine, Department of Pediatrics, Düzce, Turkey \\ 3University of Health Sciences Turkey, Kanuni Training and Research Hospital, Clinic of Pediatrics, Trabzon, Turkey
}

\begin{abstract}
Aim: The purpose of this study was to examine the effects of antiepileptics on thyroid function tests and to compare these effects among different antiepileptics.

Materials and Methods: Two hundred and twenty patients (102 female and 118 male) aged 1-17 years indicated for antiepileptic drug (AED) therapy for epilepsy were enrolled in this study which was performed in a child neurology clinic between January 2014 and January 2018. Those patients using a single AED and with complete seizure control were included. In this study period, according to the local protocol, we measured free thyroxine ( $\mathrm{fT} 4$ ) and thyroid-stimulating hormone (TSH) levels at the beginning of treatment and at the $12^{\text {th }}$ month of AED therapy.

Results: The mean age of the patients was $10.2 \pm 4.4$ years. TSH elevation was observed in only eight patients. These eight patients' thyroid autoantibodies were negative and their thyroid ultrasonography were normal. Subclinical hypothyroidism (TSH: 5-10, fT4 normal) was present in three of these eight patients, and they were therefore not started on medication. The other five were started on L-thyroxine. Four of these were using valproic acid and one was using carbamazepine. We found no significant difference between TSH and fT4 levels measured before the start and at the $12^{\text {th }}$ month of drug therapy, nor among the different AEDs used.
\end{abstract}

Conclusion: AEDs have no marked effects on thyroid function, and may therefore be safely used from that perspective.

Keywords: Antiepileptic drugs, children, epilepsy, thyroid function

\section{Introduction}

Epilepsy is the most common pediatric neurological disorder. Antiepileptic drug (AED) therapy represents the primary therapeutic option, although patients often require long-term and even life-long treatment (1).

Epilepsy and AEDs can target various substrates to affect hormone levels, including the limbic system, hypothalamus, pituitary, peripheral endocrine glands, liver, and adipose tissue $(2,3)$. Recent years have seen growing interest in the impact of epilepsy itself and of AED therapy on alterations in thyroid hormones and metabolism. Different studies evaluating thyroid functions in patients with epilepsy suggest no changes in direct association with epilepsy, although some changes in thyroid function tests may occur 
with the use of some AEDs $(3,4)$. However, other studies have reported that AEDs have no effects on thyroid function tests (5).

Many AEDs are capable of altering thyroid hormone homeostasis in terms of biosynthesis, release, transport, metabolism, and excretion of thyroid hormones. AEDs are strongly associated with decreased T4, free thyroxine (fT4), T3, and rT3 levels (6-8). It has been suggested that the alteration in thyroid parameters observed in patients using AEDs may be attributable to an effect of these drugs on binding proteins the stimulation of hepatic degradation or conjugation of thyroid hormones or a modification of peripheral deiodinase activity (9-11).

The purpose of this study was to examine the effects of antiepileptics on thyroid function tests (fT4 and TSH), and to compare these effects among different antiepileptics.

\section{Materials and Methods}

This research was designed as a retrospective hospitalbased cohort study. Two hundred and twenty patients aged 1-17 years and denoted for AED treatment for epilepsy were admitted and followed up by a single physician in a child neurology clinic between January 2014 and January 2018. Epilepsy was diagnosed based on the ILAE-2017 diagnostic and clinical criteria (12). The inclusion criteria were as follows; aged 1-17 years at diagnosis, the receipt of monotherapy with valproic acid (VPA) or another AED with follow-up for at least one year, complete control of seizures for 12 months, the absence of systemic or central nervous diseases (other than epilepsy) capable of interfering with hypothalamic-pituitary-gonadal or thyroid functions, normal findings at brain magnetic resonance imaging, and no previous treatment with AEDs, contraceptives, or hormonal or psychotropic medications. Written informed consent to participate was obtained from all families. In this study period, according to the local protocol, we measured fT4 and thyroid-stimulating hormone (TSH) levels at the beginning of treatment and at the $12^{\text {th }}$ month of AED therapy. Mean daily dosages were $30 \mathrm{mg} / \mathrm{kg} /$ day for VPA, $5 \mathrm{mg} / \mathrm{kg} /$ day for phenobarbital (PB), $30 \mathrm{mg} / \mathrm{kg} /$ day for carbamazepine (CBZ), $30 \mathrm{mg} / \mathrm{kg} /$ day for oxcarbazepine (OXC), $40 \mathrm{mg} / \mathrm{kg} /$ day for levetiracetam (LEV), $5 \mathrm{mg} / \mathrm{kg} /$ day for lamotrigine (LMT), and $5 \mathrm{mg} / \mathrm{kg} /$ day for topiramate (TPM). Patients with structural brain lesions, neuro-metabolic disease, thyroid diseases (hypothyroidism, hyperthyroidism etc.) severe mental retardation, antiseizure drug resistant seizures, or needing multi-antiseizure drug therapy were excluded. Also, those patients who missed the $12^{\text {th }}$ month check-up were excluded from the study. All electroencephalography findings of the patients were evaluated by the same child neurologist and they were classified as either mild, moderate or severe.

Patient group serum blood analyses were performed in our hospital's biochemistry laboratory. Blood samples were obtained between 08.00 a.m. and 10.00 a.m. after overnight fasting. Five cubic centiliter specimens were placed into gel-containing tubes. Care was taken to ensure that the tourniquet was applied for less than 1 minute during blood collection. Blood placed into gel-containing tubes was allowed to clot for 20 minutes at room temperature to prevent hemolysis during centrifugation. Sera were separated by centrifugation for 15 minutes at 3,000 rpm, and analysis was performed within 2 hours. Thyroid hormones and TSH were analyzed using the ECLIA method on a Boehringer Manhaim E170 device. Normal thyroid hormone levels according to that method are free T4 (fT4) $=0.93-1.7 \mathrm{ng} / \mathrm{mL}$ and $\mathrm{TSH}=0.27-4.2 \mathrm{ulU} / \mathrm{mL}$, and normal thyroid autoantibody levels are anti-thyroperoxidase $=0-34$ $\mathrm{IU} / \mathrm{mL}$ and anti-TG=0-115 $\mathrm{IU} / \mathrm{mL}$. Ethical approval for the study was granted by the Bolu Abant İzzet Baysal University Clinical Researches Ethical Committee (2020/136).

\section{Statistical Analysis}

Continuous data were expressed as mean \pm SD (minimum-maximum), and categorical variables as frequency and percentage values for each group. The Kolmogorov-Smirnov test was first applied to determine the normality of distribution of the variables. The dependent samples t-test was applied to normally distributed variables, while Pearson's chi-square test and Fisher's exact test were applied to categorical variables. The results were assessed within 95\% reliance and at a significance level of $p<0.05$. Analyses were performed on Statistical Package for Social Sciences 25.0 for Windows software (SPSS Inc., Chicago, Illinois, USA).

\section{Results}

The mean age of the 220 patients (102 female, 118 male) included in this study was $10.2 \pm 4.4$ years. Ninetyseven patients were using VPA, twenty-six were using CBZ, thirty-four were using OXC, twenty-seven were using LEV, seven were using LMT, nine were using TPM, and twenty were using PB. Mean fT4 was $1.12 \pm 0.27(0.7-2.26)$ at month 0 and $1.09 \pm 0.28(0.6-2.23)$ at month 12 , while mean TSH was $2.56 \pm 1.3(0.62-9.97)$ at month 0 and $2.82 \pm 2.02$ (0.6414.1) at 12 months (Table I). TSH elevation was detected in only eight patients during follow-up. These eight patients' thyroid autoantibodies were negative and their thyroid ultrasonography were normal. Subclinical hypothyroidism was present in three of these eight (TSH $<10$, fT4 normal), 


\begin{tabular}{|c|c|}
\hline Variables & $\mathrm{n}(\%)$ or mean $\pm \mathrm{SD}$ (range) \\
\hline Age & $10.27 \pm 4.4(1-17)$ \\
\hline \multicolumn{2}{|l|}{ Gender } \\
\hline Female & $102(46.4)$ \\
\hline Male & $118(53.6)$ \\
\hline fT4 (month 0) & $1.12 \pm 0.27(0.7-2.26)$ \\
\hline fT4 (month 12) & $1.09 \pm 0.28(0.6-2.23)$ \\
\hline TSH (month 0) & $2.56 \pm 1.3(0.62-9.97)$ \\
\hline TSH (month 12) & $2.82 \pm 2.02(0.64-14.1)$ \\
\hline \multicolumn{2}{|l|}{ AED } \\
\hline VPA & $97(44.1)$ \\
\hline CBZ & $26(11.8)$ \\
\hline OXC & $34(15.5)$ \\
\hline LEV & $27(12.3)$ \\
\hline LMT & $7(3.2)$ \\
\hline TPM & $9(4.1)$ \\
\hline PB & $20(9.1)$ \\
\hline \multicolumn{2}{|l|}{ Anti $\mathrm{Tg} / \mathrm{Tpo}$} \\
\hline No & $212(96.4)$ \\
\hline Negative & $8(3.6)$ \\
\hline \multicolumn{2}{|l|}{ Thyroid USC } \\
\hline No & $212(96.4)$ \\
\hline Thyroiditis & $8(3.6)$ \\
\hline \multicolumn{2}{|l|}{ L-tiroksin } \\
\hline No & $215(97.7)$ \\
\hline Yes & $5(2.3)$ \\
\hline \multicolumn{2}{|c|}{$\begin{array}{l}\text { Data expressed as } \mathrm{n}(\%) \\
\text { SD: Standard deviation, Ft4: Free thyroxine, TSH: Thyroid-stimulating } \\
\text { hormone, AED: Antiepileptic drug, VPA: Valproic acid, PB: Phenobarbital, CBZ: } \\
\text { Carbamazepine, OXC: Oxcarbazepine, LEV: Levetiracetam, LMT: Lamotrigine, } \\
\text { TPM: Topiramate, USG: Ultrasonography }\end{array}$} \\
\hline
\end{tabular}

and these were therefore not started on medication. The remaining five patients were started on L-thyroxine. Four of the five were using VA and one was using CBZ.

The effects of the AEDs on fT4 serum levels are shown in Table II. No statistically significant difference was determined between fT4 serum levels and the different AEDs used before the start of treatment and after 12 months of drug therapy.

The effects of the AEDs on TSH serum levels are shown in Table III. No statistically significant difference was determined between TSH serum levels and AEDs investigated before the start of treatment and after 12 months of drug therapy.

\begin{tabular}{|c|c|c|c|}
\hline Variables & fT4 (initial) & fT4 (12 month) & p-value \\
\hline \multicolumn{4}{|l|}{ AEDs } \\
\hline VPA & $1.11 \pm 0.23$ & $2.13 \pm 9.7$ & $0.3^{a}$ \\
\hline CBZ & $1.11 \pm 0.34$ & $1.0 \pm 0.18$ & $0.1^{\mathrm{a}}$ \\
\hline OXC & $3.74 \pm 1.5$ & $1.07 \pm 0.35$ & $0.32^{\mathrm{a}}$ \\
\hline LEV & $1.07 \pm 0.16$ & $1.03 \pm 0.24$ & $0.39^{a}$ \\
\hline LMT & $1.2 \pm 0.27$ & $1.04 \pm 0.24$ & $0.28^{\mathrm{a}}$ \\
\hline TPM & $1.08 \pm 0.37$ & $0.9 \pm 0.15$ & $0.1^{\mathrm{a}}$ \\
\hline PB & $1.28 \pm 0.38$ & $1.2 \pm 0.27$ & $0.33^{\mathrm{a}}$ \\
\hline \multicolumn{4}{|c|}{$\begin{array}{l}\text { aPaired sample t-test } \\
\text { AED: Antiepileptic drug, Ft4: Free thyroxine, VPA: Valproic acid, CBZ } \\
\text { Carbamazepine, OXC: Oxcarbazepine, LEV: Levetiracetam, LMT: Lamotrigine, } \\
\text { TPM: Topiramate, PB: Phenobarbital }\end{array}$} \\
\hline
\end{tabular}

Table III. Effects of AEDs on TSH

\begin{tabular}{|c|c|c|c|}
\hline Variables & TSH (initial) & TSH (12 month) & p-value \\
\hline \multicolumn{4}{|l|}{ AEDs } \\
\hline VPA & $2.82 \pm 1.51$ & $3.07 \pm 2.28$ & $0.22^{\mathrm{a}}$ \\
\hline CBZ & $2.26 \pm 1.05$ & $2.69 \pm 2.0$ & $0.26^{\mathrm{a}}$ \\
\hline OXC & $2.3 \pm 1.19$ & $2.41 \pm 1.39$ & $0.64^{a}$ \\
\hline LEV & $2.1 \pm 0.85$ & $2.34 \pm 1.5$ & $0.44^{\mathrm{a}}$ \\
\hline LMT & $2.54 \pm 0.84$ & $3.1 \pm 2.4$ & $0.1^{\mathrm{a}}$ \\
\hline TPM & $3.07 \pm 1.42$ & $2.76 \pm 1.8$ & $0.6^{a}$ \\
\hline PB & $2.46 \pm 0.9$ & $3.02 \pm 2.24$ & $0.29^{a}$ \\
\hline \multicolumn{4}{|c|}{$\begin{array}{l}\text { aPaired sample t-test } \\
\text { TSH: Thyroid-stimulating hormone, AED: Antiepileptic drug, VPA: Valproic } \\
\text { acid, CBZ: Carbamazepine, OXC: Oxcarbazepine, LEV: Levetiracetam, LMT: } \\
\text { Lamotrigine, TPM: Topiramate, PB: Phenobarbital }\end{array}$} \\
\hline
\end{tabular}

\section{Discussion}

This study determined no statistically significant effects on thyroid functions for drugs such as VPA, CBZ, OXC, $L E V, F B, T P M$, and LMT used as single antiepileptics. Also, no significant differences between these medications in terms of thyroid function tests were determined. TSH elevation was detected in eight patients (3.6\%) at the end of a 12-month follow-up of thyroid dysfunction. Subclinical hypothyroidism was detected in three of these, who were therefore not started on medication. Five patients were started on L-thyroxine due to TSH elevation and low fT4. Four of these patients were using VPA and one was using CBZ. Some studies have reported that antiepileptics, and particularly VPA, have adverse effects on thyroid function tests $(13,14)$, while others have reported no effect $(5)$.

One study comparing 41 epileptic patients using VPA with a control group reported significant elevation in $\mathrm{fT} 4$ and 
TSH levels, particularly in the first four years of treatment, in approximately one in three patients using VPA (13). A similar study compared 61 epileptic children using VPA with a 144-member healthy control group and reported a higher incidence of subclinical hypothyroidism in the VPA group (14). Based on these findings, those authors suggested that subclinical hypothyroidism may frequently emerge during VPA use. Although the follow-up period was shorter in the present study, we detected hypothyroidism in only four patients using VPA, and subclinical hypothyroidism in three patients. Caksen et al. (5) compared thyroid and parathyroid functions in 31 patients with epilepsy using VPA with an aged-matched control group and reported no effect of longterm VPA therapy on thyroid and parathyroid functions in children. In addition, they concluded that VPA can be safely used in children from that perspective without causing thyroid or parathyroid dysfunction.

Another study in which 42 girls used VPA and 15 used other AEDs reported higher TSH levels at six and 12 months in the VPA group with thyroid function tests performed at months 0,6 , and 12 , while no significant difference was observed between VPA and other AEDs in terms of mean fT4 levels (15). In the present study, we determined no significant difference between fT4 or TSH levels at months 0 and 12 .

In another study involving 183 pediatric epilepsy patients using VPA or PB and 151 healthy controls, subclinical hypothyroidism was detected at month 12 in $15.2 \%$ of the VPA group and in $2.9 \%$ of the PB group. A statistically significant difference was observed in the incidence of subclinical hypothyroidism in the VPA group compared with pre-treatment values, while no significant difference was found in the PB group (16). The rate of development of hypothyroidism in the VPA group in the present study was $4.1 \%$ (4/97), and no significant difference was determined compared to other AEDs.

A prospective study of 21 epileptic patients using LEV or CBZ investigated thyroid function tests and lipid profile values before the commencement and one and six months after the commencement of medication. The authors reported a significant decrease in fT4 levels in the CBZ group but no significant change in fT4 or TSH levels in the LEV group (17). TSH elevation and low fT4 were determined in only one patient receiving CBZ in the present study. We observed no significant change in fT4 or TSH levels in those patients using LEV. There was also no difference between the two drugs from that perspective.
A study of 223 patients with controlled epilepsy using single AEDs investigated fT4 and TSH levels at months 0 , 6 , and 12. Lower serum fT4 levels and increased serum TSH levels were reported in those patients treated with VPA compared to those using $\mathrm{CBZ}$, OXC, or FB. No difference in thyroid function tests was observed in patients using (18). In the present study, TSH elevation and low fT4 were detected in four patients using VPA and one using CBZ, while no difference in thyroid functions tests was found in any of the other AEDs.

A study involving 78 girls receiving $C B Z$, OXC, or VPA monotherapy and a 54-member healthy control group reported low fT4 and normal TSH in the CBZ and OXC groups, compared to normal fT4 and high TSH in the VPA group (19). We detected no difference between mean fT4 and TSH in the present study.

Garoufi et al. (20) investigated 23 children aged 5-15 years using OXC and measured fT 4 and TSH levels before the start of drug therapy and after 8 and 18 months. fT 4 was significantly decreased at 8 and 18 months ( $p<0.001$ and $p=0.002$, respectively), while TSH levels were significantly increased at 8 and 18 months. In the present study, there was no difference between either fT4 or TSH levels at months 1 and 12 .

Consistent with the results of the present research, another study of 53 patients aged 3-17 years using VPA, CBZ or OXC monotherapy also observed no difference in thyroid function tests and thyroid volumes between the study groups. The authors of that study detected hypothyroidism based on the thyrotropin-releasing hormone stimulation test in six patients using VPA, in one using $C B Z$, and in one using OXC (21).

In a study of 106 patients aged from 3 months to 14 years using VPA, CBZ, OXC, LEV, TPM, or PB monotherapy, fT4 and TSH levels were measured at the start of treatment and at months 3, 6, and 9. No significant differences were observed in mean $\mathrm{fT} 4$ values between the drug groups. However, the mean fT4 levels of the patients in the VPA group exhibited a decrease within the observation period. No significant difference was observed in mean TSH values between the groups at the beginning and at the third and sixth months. However, by the $9^{\text {th }}$ month, TSH values had increased significantly in the VPA group. In the VPA group, mean TSH values rose progressively but remained within normal limits. Thyroid dysfunction was detected in 21 patients during follow-up (19.6\%). The authors of that study suggested that VPA use might lead to thyroid dysfunction in epileptic patients (22). 


\section{Study Limitations}

The limitations of the present study include its retrospective nature, the lack of a healthy control group, the follow-up period being restricted to 12 months, and thyroid function tests not being investigated between months 0 and 12. However, the particular strengths of the study include the high patient number and that the hitherto unexamined relationship between AEDs and thyroid function tests was investigated.

\section{Conclusion}

In conclusion, AEDs have no marked effect in terms of thyroid functions, and may therefore be used safely from that perspective. However, further prospective studies involving larger patient numbers and followed up for longer periods are needed with regard to this subject.

\section{Ethics}

Ethics Committee Approval: Ethical approval for the study was granted by the Bolu Abant İzzet Baysal University Clinical Researches Ethical Committee (2020/136).

Informed Consent: Written informed consent to participate was obtained from all families.

Peer-review: Externally peer-reviewed.

\section{Authorship Contributions}

Concept: F.H., K.A.B., Design: F.H., K.A.B., N.K., Data Collection or Processing: A.T., Analysis or Interpretation: M.D., Literature Search: S.T., Writing: N.K.

Conflict of Interest: None of the authors had conflict of interest.

Financial Disclosure: The authors declared that this study received no financial support.

\section{References}

1. Freitag CM, May TW, Pfäfflin M, König S, Rating D. Incidence of epilepsies and epileptic syndromes in children and adolescents: a population-based prospective study in Germany. Epilepsia 2001; 42:979-85.

2. Herzog AG. Neuroendocrinology: Epilepsy. Continuum (Minneap Minn) 2009; 15:37.

3. Pennell PB. Hormonal aspects of epilepsy. Neurol Clin 2009; 27:941-65.

4. Cansu A. Antiepileptic drugs and hormones in children. Epilepsy Res 2010; 89:89-95.

5. Caksen H, Dülger $H$, Cesur $Y$, Odabaş $D$, Tuncer $O$, Ataş $B$. No effect of long-term valproate therapy on thyroid and parathyroid functions in children. Int / Neurosci 2002; 12:1371-4.

6. Liewendahl K, Majuri $\mathrm{H}$, Helenius T. Thyroid function tests in patients on long-term treatment with various anticonvulsant drugs. Clin Endocrinol (Oxf) 1978; 8:185-91.
7. Verrotti A, Laus M, Scardapane A, Franzoni E, Chiarelli F. Thyroid hormones in children with epilepsy during longterm administration of carbamazepine and valproate. Eur I Endocrinol 2009; 160:81-6.

8. Lossius MI, Taubøll E, Mowinckel P, Gjerstad L. Reversible effects of antiepileptic drugs on thyroid hormones in men and women with epilepsy: a prospective randomized double-blind withdrawal study. Epilepsy Behav 2009; 16:64-8.

9. Surks MI, DeFesi CR. Normal serum free thyroid hormone concentrations in patients treated with phenytoin or carbamazepine. A paradox resolved. JAMA 1996; 275:1495-8.

10. Liewendahl K, Helenius T, Majuri H, Ebeling P, Ahlfors UG. Effect of anticonvulsant and antidepressant drugs on iodothyronines in serum. Scand I Clin Lab Invest 1980; 40:767-74.

11. Visser WE, de Rijke YB, van Toor H, Visser TJ. Thyroid status in a large cohort of patients with mental retardation: the TOP-R (Thyroid Origin of Psychomotor Retardation) study. Clin Endocrinol (Oxf) 2011; 75:395-401.

12. Fisher RS, Cross JH, D'Souza C, et al. Instruction manual for the ILAE 2017 operational classification of seizure types. Epilepsia 2017; 58:531-42.

13. Ilić V, Bogićević D, Miljković B, et al. Duration of valproic acid monotherapy correlates with subclinical thyroid dysfunction in children with epilepsy. Epileptic Disord 2016; 18:181-6.

14. Kim SH, Chung HR, Kim SH, et al. Subclinical hypothyroidism during valproic acid therapy in children and adolescents with epilepsy. Neuropediatrics 2012; 43:135-9.

15. Goldberg-Stern H, Yaacobi E, Phillip M, de Vries L. Endocrine effects of valproic acid therapy in girls with epilepsy: a prospective study. Eur I Paediatr Neurol 2014; 18:759-65.

16. Güngör $O$, Özkaya AK, Temiz F. The effect of antiepileptic drugs on thyroid hormonal function: valproic acid and phenobarbital. Acta Neurol Belg 2020; 120:615-9.

17. Nishiyama M, Takami Y, Ishida Y, et al. Lipid and thyroid hormone levels in children with epilepsy treated with levetiracetam or carbamazepine: a prospective observational study. Epilepsy Behav 2019; 90:15-9.

18. Yılmaz U, Yılmaz TS, Akıncı G, Korkmaz HA, Tekgül H. The effect of antiepileptic drugs on thyroid function in children. Seizure 2014; 23:29-35.

19. Vainionpää LK, Mikkonen K, Rättyä J, et al. Thyroid function in girls with epilepsy with carbamazepine, oxcarbazepine, or valproate monotherapy and after withdrawal of medication. Epilepsia 2004; 45:197-203.

20. Garoufi A, Koemtzidou E, Katsarou E, et al. Lipid profile and thyroid hormone concentrations in children with epilepsy treated with oxcarbazepine monotherapy: a prospective longterm study. Eur / Neurol 2014; 21:118-23.

21. Hirfanoglu T, Serdaroglu A, Camurdan O, et al. Thyroid function and volume in epileptic children using carbamazepine, oxcarbazepine and valproate. Pediatr Int 2007; 49:822-6.

22. Aygün F, Ekici B, Aydinli N, Aydin BK, Baş F, Tatli B. Thyroid hormones in children on antiepileptic therapy. Int J Neurosci 2012; 122:69-73. 